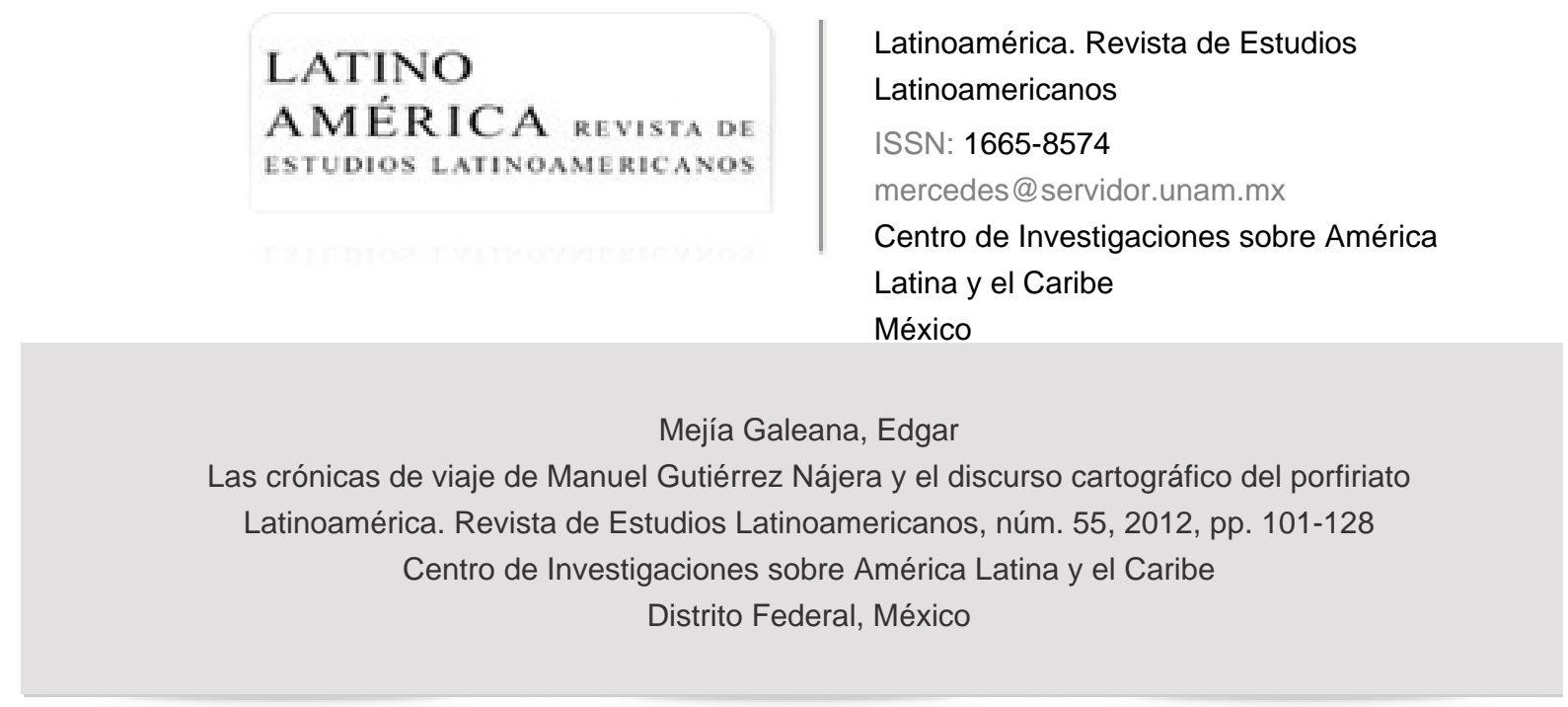

Disponible en: http://www.redalyc.org/articulo.oa?id=64024698005

- Cómo citar el artículo

- Número completo

- Más información del artículo

- Página de la revista en redalyc.org

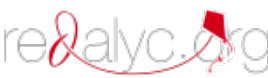

Sistema de Información Científica

Red de Revistas Científicas de América Latina, el Caribe, España y Portugal Proyecto académico sin fines de lucro, desarrollado bajo la iniciativa de acceso abierto 


\title{
DPROMMATCOSYVIAEROS
}

\section{Las crónicas de viaje de Manuel Gutiérrez Nájera y el discurso cartográfico del porfiriato}

\author{
Edgar Mejía Galeana*
}

Resumen: Este artículo examina las crónicas de viaje de Manuel Gutiérrez Nájera publicadas entre 1880 y 1893 en el contexto de la reorganización física y discursiva del territorio nacional como parte de las aspiraciones de modernidad de la elite porfirista. En esta lectura, las crónicas de Nájera recuperan su legitimidad como discursos sobre el espacio, perdida la raíz de la instituciona lización de la geografía y por la masificación de la práctica del viaje, a partir de su confirmación y refuerzo de la visión del espacio nacional promovido por las instituciones geográficas porfiristas que formulan la idea de un México abierto, moderno e integrado a los centros de la modernidad capitalista.

Palabras Clave: Literatura de viaje, Cartografía, Modernización, Espacio nacional, Ferrocarriles, Manuel Gutiérrez Nájera.

ABSTRACT: This article examines the travel chronicles written by Manuel Gutiérrez Nájera between 1880 and 1893 in the context of the physical and discursive reorganization of the national space promoted by the Porfirian elite. From this point of view, the accounts by Nájera negotiate their legitimacy as a discourse about space -lost in part by the increasing institutionalization of cartography and the massive growth of travel - by strengthening the notion promoted by Porfirian geographical institutions of Mexico as a modern and open nation, integrated to the hegemonic centers of capitalist modernity.

Key words: Travel Writing, Cartography, Modernity, National Space, Manuel Gutiérrez Nájera.

Providence College, Rhode Island, Estados Unidos (emejia@providence.edu). 


\section{LA “LLEGADA” DE LA MODERNIZACIÓN}

fines del siglo xIx, el discurso letrado creía que América Latina for-
maba parte, finalmente, de la modernidad occidental. Las últimas dé-
cadas del siglo xIx y la primera del xx fueron vividas, al menos por las
élites que pudieron comparar el atraso latinoamericano frente al progreso euro-norteamericano, como el final de un aislamiento. Cierta prosperidad económica, la disponibilidad de nuevas tecnologías de transporte y el advenimiento de algunas comodidades hicieron pensar a las élites económicas, políticas y culturales en que las distancias respecto a los centros hegemónicos se habían reducido.

La manera en que se nombra la reproducción del fenómeno de la modernización en el contexto latinoamericano tiene a veces un sentido espacial: la "entrada" a la modernidad, la "llegada" de la modernidad a América Latina. En ambos casos, aunque señalan flujos opuestos, se supone un espacio en que estos cambios tienen su origen y en donde comienza su difusión o adopción. La bibliografía sobre la literatura de fin de siglo, sobre el modernismo en particular, ha insistido mucho en que el estudio de la literatura de ese periodo debe pasar por la consideración de la integración de América Latina al capitalismo internacional. ${ }^{1}$

El interés por la modernidad latinoamericana comienza a diseñar un nuevo campo de cruces disciplinarios en los que los relatos latinoamericanos sobre la modernidad ("discursos de la modernidad") son vistos no sólo como cifras de fenómenos económicos, sino como prácticas culturales interesantes en sí mismas, en la medida en que designan historias de apropiaciones históricas e identitarias. ${ }^{2}$ La incursión crítica que no ha sido tan frecuente, en cambio, es aquella que relataría, desde el punto de vista de la espacialidad, ${ }^{3}$ la manera en que la

1 Véase Françoise Perus, Literatura y sociedad en América Latina: el modernismo, México, Siglo xxI, 1976; Susana Rotker, Fundación de una escritura: las crónicas de José Martí, La Habana, Casa de las Américas, 1992.

2 Carlos J. Alonso, The Spanish American Regional Novel y The Burden of Modernity son ejemplos de este enfoque crítico.

3 Aquí me refiero al "giro espacial" que se produjo en las ciencias sociales a partir de la obra de Henri Lefebvre, en la que la "dialéctica temporal", que había dominado la teoría marxista, es 
literatura y los sujetos asimilan la serie de cambios socioeconómicos y culturales del fin de siglo. Si como ya ha demostrado Julio Ramos, la crónica fue el género que por su heterogeneidad permitió relatar la intensa modernización del fin de siglo, ${ }^{4}$ me parece que la crónica de viajes, en sus relatos de desplazamientos, flujos y cruces fronterizos, permite leer la manera en que se plasmó el sueño de modernidad espacialmente.

En México podemos pensar las crónicas de viaje modernistas como discursos de la modernidad, en la medida en que eran el relato de la experiencia en el espacio modernizado que la cartografía porfirista promovía. En este trabajo me propongo hacer una lectura de las crónicas de viaje de Manuel Gutiérrez Nájera frente a la emergencia de la geografía como discurso autorizado del espacio. En mi lectura, las crónicas de viaje de Nájera, a pesar de haber sido relegadas a los márgenes por las instituciones geográficas, refuerzan las premisas de la cartografía porfirista de mostrar el territorio nacional como parte del espacio de la modernidad occidental. Este trabajo está lejos de intentar un análisis del estado del "discurso social" a finales del siglo xIx, como lo entiende Angenot, pero quiere al menos resituar las crónicas de viaje de Nájera dentro de esa red de discursos sobre el espacio que fueron impulsados desde el Estado porfirista. ${ }^{5}$ La premisa del trabajo es que la noción de espacio nacional formaba

sustituida por una interrogación sobre la manera en que el capitalismo es decir, la manera en que ha reproducido el espacio, a escala espacial, en las condiciones de producción, trabajo y consumo que lo sostiene, la manera en que ha "producido el espacio" como una más de sus mercancías. Para una revisión teórica de este cambio, véase Edward W. Soja, Postmodern Geographies: The Reassertion of Space in Critical Social Theory, Londres, Verso, 1989.

4 Julio Ramos, Desencuentros de la modernidad en América Latina. Literatura y política en el siglo XX, México, FCE, 1989, p. 113.

5 Para Marc Angenot el estudio de la literatura sólo puede ser emprendido como parte de una exploración mayor del "discurso social", que es definido como la suma de "sistemas genéricos, de repertorios de tópicos, de reglas que vinculan las expresiones en una determinada sociedad, los cuales organizan lo decible - eso que puede ser narrado y comentado- y que asegura la división del trabajo discursivo" (citado en Michael Pierssens, "A State of Social Discourse", en The Yale Journal of Criticism 17.2, trad. del francés por Robert Barsky, 2004, p. 256, la traducción al español es mía). En ese sentido, "los textos literarios (y otros) deben ser abordados y analizados como aparatos intertextuales que seleccionan, absorben, transforman y re-difunden ciertas imágenes, máximas y nociones que migran a lo largo de la red socio-discursiva [...]. 
parte del discurso social del México finisecular; mi propósito entonces es comenzar a explorar la manera en que los discursos cartográfico y literario-periodístico intentaron crear las condiciones de posibilidad para imaginar el territorio nacional como un espacio integrado a la modernidad capitalista mundial

\section{EL SUEÑO MODERNO}

En 1881 José María Velasco (1840-1912) pintó un cuadro, La Cañada del Metlac, que se convertiría en el emblema de la modernidad deseada por la élite porfirista. En el margen superior izquierdo del cuadro domina la silueta del volcán Popocatépetl y, a la derecha, se despliega una cadena montañosa que se prolonga hasta el horizonte. El centro del cuadro lo domina la cañada sobre la que cae una sombra que insinúa una topografía accidentada; un poco más abajo se ve el río Metlac que da vuelta y se pierde en la abundante vegetación que domina todo el margen inferior izquierdo. De la parte derecha, casi imitando la curva que dibuja el río, emerge una locomotora que arroja un humo negro espeso. Las líneas rectas de la locomotora y los vagones que se alcanzan a ver dan la impresión, por un momento, de separar al tren de esa naturaleza accidentada que recorre, pero los tonos oscuros de la cañada y el negro grisáceo del tren suavizan el contraste, y terminan por armonizar naturaleza y tecnología.

La élite porfirista, tan proclive a la profusión y difusión de imágenes, encontró en el cuadro de Velasco el emblema perfecto del credo progresista. A la exaltación nacionalista del paisaje, Velasco aunó el símbolo moderno de la época por excelencia, el ferrocarril. La dimensión que agregaba el ferrocarril al paisaje mexicano era el dinamismo de los nuevos tiempos. La sintonía que el cuadro afir-

Los textos sólo tienen sentido dentro de la red intertextual que ellos evocan y con la que antagonizan", Marc Angenot, "Social Discourse Analysis: Outlines of a Research Project", en The Yale Journal of Criticism 17.2, 2004, p. 212. La traducción es mía. 
maba con los cambios recientes de orden global reforzaba su carácter programático y explica el interés de la élite en poseerlo y exhibirlo públicamente. ${ }^{6}$

La imagen del ferrocarril que resignifica la naturaleza mexicana encarna eso que, para Rafael Pérez Gay, fue la metáfora privilegiada del porfiriato, el viaje: "[...] el abandono de la orilla miserable del pasado para dirigirse al paraíso de la modernidad." 7 Pero la metáfora del viaje, o de manera más general, el desplazamiento, designa otros dos de los programas de Estado que caracterizaron la gestión porfirista: el estímulo a la inmigración europea y la captación de inversión foránea. A partir de esos dos desplazamientos, de mano de obra y capital, se pensaba, se pondrían las bases de la futura modernidad. La inmigración europea nunca se produjo en las cantidades que las élites porfiristas deseaban y la inversión extranjera fue el resultado inevitable de la expansión capitalista que, a fines del siglo XIX, convirtió la economía-mundo en una gran "empresa global", a la que fue integrada la economía de regiones que hasta entonces habían sido excluidas del circuito capitalista. ${ }^{8}$

La llegada de Porfirio Díaz al poder (1876) coincidió con una serie de transformaciones socioeconómicas a escala mundial que constituyen la esencia de la modernización: expansión del capitalismo, burocratización de los estados nacionales, industrialización y crecimiento de los centros urbanos (y predomino de la cultura urbana, en general). Díaz y sus colaboradores vieron con optimismo los cambios que presionaban desde fuera y los apoyaron incondicionalmente. La "fiebre ferrocarrilera", como la llamó Manuel Gutiérrez Nájera en una de sus crónicas, respondía a una política sobre el espacio que venía dictada por los paí-

6 Miguel Tenorio-Trillo, Artilugio de la nación moderna. México en las exposiciones universales, 1880-1930, México, FCE, 1998, analiza ampliamente la participación de José María Velasco en la promoción de una imagen moderna de México durante el porfiriato; sobre esta pintura en particular, véanse pp. 162 y 163.

7 Rafael Pérez Gay, "Prólogo" a Manuel Gutiérrez Nájera, México, Cal y Arena, 1996 (Col. Los imprescindibles), p. vii.

8 Inmanuel Wallerstein, El moderno sistema mundial. La segunda era de gran expansión de la economía-mundo capitalista, 1730-1850, trad. de Jesús Albores, México, Siglo xxI, 1998, vol. 3, p. 179. 
ses centrales del sistema-mundo capitalista. ${ }^{9}$ Sólo para historizar esa iconografía de la modernidad que es el cuadro de Velasco: en 1889 las vías férreas alcanzaban los 10 mil kilómetros, y a partir de entonces cada año se sumaban 500 kilómetros más en promedio. ${ }^{10}$ Por esos años se habían dado concesiones para la construcción de vías férreas a casi 50 compañías extranjeras. Durante el porfiriato se consolidaron, pues, dos fenómenos exigidos por el nuevo orden capitalista en relación con el manejo del espacio nacional: el crecimiento de la infraestructura del transporte y la privatización de la tierra. ${ }^{11}$

\section{EL DISCURSO CARTOGRÁFICO DEL PORFIRIATO}

Para Mauricio Tenorio-Trillo, el periodo de 1880 a 1930, que abarca todo el porfiriato y los regímenes revolucionarios, está marcado por un desarrollo de lo que él llama la "infraestructura nacionalista", que consistía en crear "una imagen de la nación en los tiempos modernos." ${ }^{12}$ El historiador dedica varios capítulos al análisis de la exposición internacional de 1889 de París, en la que la élite porfirista usó, como nunca antes, su maquinaria políica, intelectual y artística para crear una imagen de lo nacional que exhibiera la "modernidad" mexicana y que sirviera para tramitar el ingreso del país a la economía-mundo capitalista. Producir esa imagen supuso la movilización de ciertos saberes, que al mismo tiempo que con-

9 Para el geógrafo David Harvey a cada fase del capitalismo le corresponde una reorganización de los espacios para adaptarlos a las nuevas formas de circulación del capital.

${ }^{10}$ Luis González, "El liberalismo triunfante", en Historia General de México, México, Centro de Estudios Históricos-El Colegio de México, 1998, vol. 2, p. 235.

${ }^{11}$ Los años del porfiriato vieron el auge de las "compañías deslindadoras" que hicieron el trabajo de relevamiento de las tierras comunales, que se consideraban improductivas de acuerdo a los nuevos estándares modernos, para ofrecerlas a los inversionistas privados. Para una revisión exhaustiva al proyecto porfirista de privatización de la tierra, véase R. H. Holden, Mexico and the Survey of Public Lands: The Management of Modernization, 1876-1911, Dekalb, Northern Illinois up, 1994.

12 Tenorio-Trillo, op. cit., p. 321. 
currían a la elaboración del discurso nacionalista, iban definiendo sus campos de especialización y se "modernizaban", modelados siempre desde el centro. ${ }^{13}$

Me interesa detenerme en el desarrollo que tuvo la geografía, y en especial la cartografía, durante el porfiriato, porque su desarrollo es un índice de la imagen que el Estado quería dar de sí mismo. Si a mediados del siglo xix la cartografía mexicana sirvió como conciencia territorial ${ }^{14}$ de un país cuyos límites habían sido recientemente re-trazados por la guerra con Estados Unidos (1848), cuya vecindad se percibía como una amenaza de más pérdidas territoriales, durante el porfiriato la intensa producción cartográfica y la progresiva profesionalización de la disciplina geográfica tienen su correlato en la edificación de un Estado que se concebía como moderno.

Si bien es cierto que los mapas descriptivos de Antonio García Cubas se exhibieron en las primeras exposiciones universales en las que participó México, paulatinamente se fueron incorporando a los catálogos los mapas elaborados, con métodos más rigurosos, por la institución que aglutinó las labores geográficas durante el porfiriato, la Comisión Geográfico-Exploradora (CGE). ${ }^{15}$ Para el gobierno de Díaz, la fundación de la Comisión representaba la posibilidad de

${ }^{13}$ La arquitectura mexicana, a partir de la discusión sobre la construcción del "Palacio azteca", ingresó al debate sobre el nacionalismo, que en literatura había comenzado a mediados de siglo. La historia produjo la primera obra general sobre la historia de México en la que participaron historiadores de distintas tendencias políticas: México a través de los siglos de Vicente Riva Palacio.

${ }^{14}$ Escribe Craib a propósito de los mapas mexicanos de mediados de siglo: "Tales mapas fueron también discursos históricos que ofrecieron la memoria de un cuerpo social homogéneo, utilizando la ciencia y el arte en un intento por combinar la historia y la geografía", Raymond B. Craib, "El discurso cartográfico en el México del porfiriato", en Héctor Mendoza Vargas y Michel Antochiw [eds.], México a través de los mapas, México, Instituto de Geografía-unam, 2000, p. 133.

15 La década de 1880 fue el periodo más intenso de colaboración de Antonio García Cubas con las instituciones porfiristas: la Sociedad Mexicana de Geografía y Estadística y, sobre todo, con la Secretaría de Fomento. En 1885 publicó su Cuadro geográfico, estadístico, descriptivo e histórico de los Estados Unidos Mexicanos, que sirvió como "explicación" a su Atlas pintoresco y que fue traducido al inglés y al francés años más tarde para servir a la promoción del territorio nacional en el ámbito internacional. En 1887 publicó el Atlas geográfico y estadístico de los Estados Unidos Mexicanos que había elaborado y publicado originalmente en 1858; dado que el propósito era exhibirlo en la Exposición Universal de 1899, esta nueva edición incorporó 
aglutinar todos los conocimientos sobre el espacio nacional en una sola institución. ${ }^{16}$ La Comisión operó durante la mayor parte de su existencia como una entidad vinculada al ejército; durante los primeros años el número de militares empleados superaba al de civiles. ${ }^{17}$ Dos razones explican esta militarización de la Comisión; en primer lugar, el hecho de que para Díaz el conocimiento geográfico tenía un carácter estratégico y, en segundo, a que durante las primeras décadas el gobierno de Díaz fue sobre todo un régimen militar. ${ }^{18}$ Sin embargo, a pesar de la importancia política-militar concedida a la Comisión, ésta comenzó a laborar con un presupuesto restringido, de manera que además del cumplimiento de sus tareas científicas, los miembros de la Comisión tuvieron que convencer a la administración de Díaz de la necesidad de un financiamiento mayor.

El objetivo principal en torno al cual se unificaron todas las tareas geográficas del Estado era la elaboración de un "Carta general de México" a la escala 1: 100000 que, a diferencia de los mapas existentes, sistematizaría el conocimiento sobre el territorio, permitiría un mayor control sobre él, resolvería conflictos de tierras y reordenaría la toponimia, que durante el siglo xIX causó tantas polémicas; dicho mapa sería elaborado a partir de un extenso trabajo de campo. A diferencia de los mapas de García Cubas, que fueron elaborados a partir de información recabada por otras fuentes, el mapa general sería elaborado a partir de cálculos astronómicos y triangulaciones geométricas. ${ }^{19} \mathrm{La}$ carta general permitiría, sin duda, establecer los límites de la soberanía del Estado, inventariar

datos más precisos proporcionados por la Comisión Geográfico-Exploradora, y destacaba de manera detallada las líneas de ferrocarril y telégrafos.

${ }^{16}$ Entiendo por espacio nacional la apropiación discursiva y política del territorio en que se asienta el Estado-nación y sobre el que ejerce su soberanía y su proyecto político. Para una discusión sobre el concepto de territorio y espacio nacional, véase Ighina et al., Espacios geoculturales. Diseños de nación en los discursos literarios del Cono Sur. 1880-1930, Córdoba, Alción, 2000, especialmente la introducción al volumen.

${ }^{17}$ Para detalles sobre los métodos empleados por la Comisión Geográfico-Exploradora, véase Bernardo García Martínez, "La Comisión Geográfico-Exploradora", en Historia mexicana, núm. 96, abril-junio 1975, pp. 485-555.

${ }^{18}$ Raymond B. Craib, Cartographic Mexico: A History of State Fixations and Fugitive Landscapes, Durham, Duke UP, 2004, p. 137.

19 Craib, "El discurso cartográfico...", pp. 130 y 131. 
los espacios en que se ejercerá el proyecto político y presentar una imagen moderna de sí mismo en el exterior.

En 1889 los miembros de la CGE elaboraron el plan de un mapa, que se pensaba exhibir en la Exposición Universal de ese año, en el que se tendrían que destacar los siguientes aspectos:

[...] el clima de México, favorable para la agricultura; la ciudad de México, prueba de la modernidad de México; la organización política y social de México, al mismo tiempo demostración de la existencia de un orden y explicación de las facilidades burocráticas y financieras ofrecidas por el Estado a los inversionistas e inmigrantes; la extensión y calidad del sistema de comunicaciones de México, en especial telégrafos y ferrocarriles; la cantidad y calidad arquitectónica de edificios públicos y monumentos, ejemplo de los avances republicanos y estéticos de México $[\ldots]^{20}$

Aunque el mapa no se llegó a elaborar de acuerdo al plan establecido, demuestra, al menos, las aspiraciones del gobierno porfirista en cuanto a la difusión de la imagen cartográfica del México "moderno". Al gobierno de Díaz, sin embargo, no sólo le interesaba exhibir una imagen de modernidad en el exterior, en las exposición universales sobre todo, sino que el impulso que recibió el ejercicio cartográfico a fines del XIX se explica también por el interés en "popularizar la geografía del país" ${ }^{\prime 1}$ al interior, a través de la producción de mapas a precio reducido que fueran accesibles al público. De manera que la práctica geográfica durante el porfiriato se constituyó realmente en eso que Craib ha denominado como un "discurso cartográfico", en la medida en que creó una idea de espacio nacional y proyectó una imagen general de la nación. No pretendo hacer un relato detallado de la manera en que la cartografía plasmó topográficamente el sueño moderno porfiriano, pero sí me interesa destacar un mapa que muestra la forma en que el proyecto modernizador del porfirismo produjo una imagen del espacio nacional. El mapa de Francisco A. Calderón, "Carta pos-

${ }^{20}$ Tenorio-Trillo, op. cit., p. 182.

${ }^{21}$ Véase Agustín Díaz, "Informe del estado actual de la cartografía", citado en García Martínez, op. cit., p. 488. 
tal y de vías de comunicación de México, 1910", quizá sea el ejemplo más notable del "discurso cartográfico del porfiriato", y puede considerarse, casi en el último año de la dictadura porfirista, como el punto culminante de su impulso a la actividad cartográfica (fig. 1). ${ }^{22}$

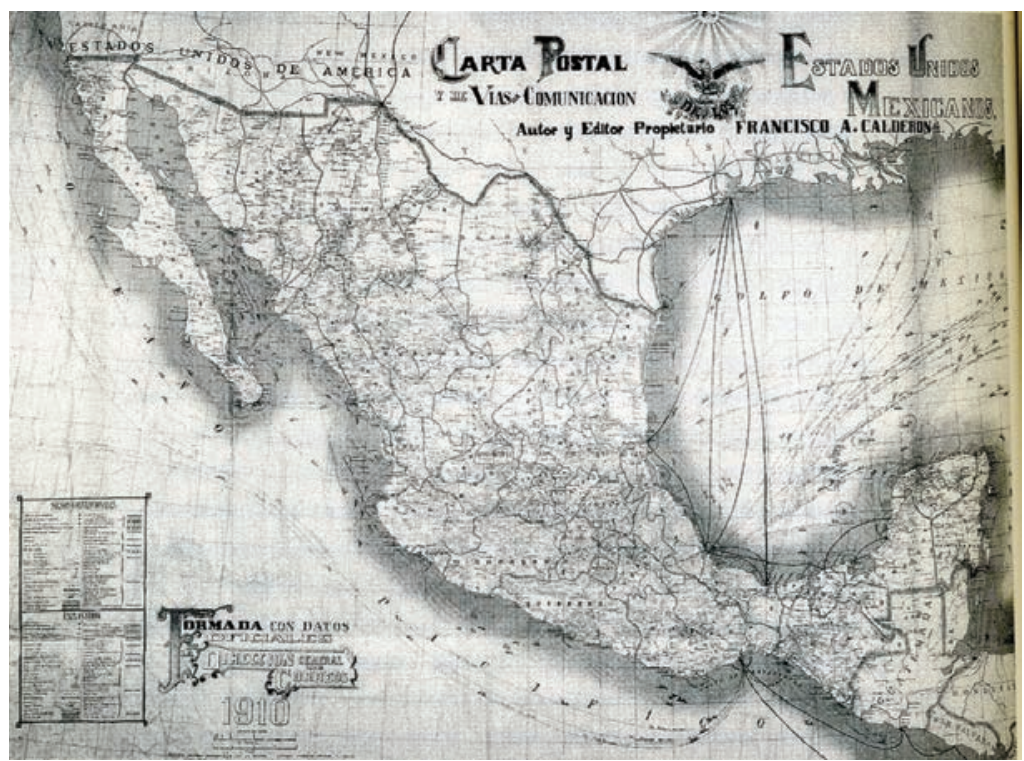

Figura 1. Francisco A. Calderón, Carta postal y de vías de comunicación de México, 1910.

En el mapa de Calderón el espacio de la nación está atravesado por caminos, líneas telegráficas y vías férreas; muestra, no sólo la apertura y accesibilidad del territorio mexicano, su disponibilidad para la inversión, sino también la racionalidad económica con que el Estado mexicano ha administrado su territorio. Para David Harvey, el control del espacio requiere que sea concebido como "usable", "manejable" y capaz de ser transformado a través de la acción humana.

${ }^{22}$ El mapa forma parte del acervo de la Mapoteca Manuel Orozco y Berra y está reproducido en Craib, Cartographic..., p. 183. 
La cartografía matemática y científica es para él el instrumento que homogeneiza y universaliza el espacio. ${ }^{23}$ El mapa de Calderón denota un dominio, una "conquista" del Estado sobre el espacio nacional; ya no se trata del espacio abrumadoramente desconocido de comienzos de siglo, sino de un espacio económico que en los flujos que lo atraviesan expresa su pertenencia a la modernidad global. Y al mismo tiempo es un enunciado que alude a la capacidad del Estado mexicano de realizar proyectos científicos modernos.

\section{El VIAJE NACIONALISTA: IGNACIO M. ALTAMIRANO}

Según Jens Andermann a partir de la introducción de los ferrocarriles, la crónica de viaje decimonónica pierde legitimidad: "Cuando ya se puede viajar sin grandes inconvenientes a los puntos cardinales del país, la legitimidad del relato de viajes entra en crisis. ${ }^{24}$ Con todo y ser cierto, me parece que la profesionalización de la geografía contribuyó de una manera más determinante a la pérdida de legitimidad de la crónica de viajes para producir discursos sobre el espacio nacional. Si a mediados del siglo xIx las crónicas de viaje de Manuel Payno podían aparecer en el Boletín de la Sociedad de Geografía y Estadística como parte de los intentos por "aprender" el territorio, a fines de siglo los relatos de viajes pierden su condición de "máquinas territorializadoras" — como las llama Montaldo-, ${ }^{25}$ en la medida en que es ahora el discurso geográfico el que da cuenta del territorio de una manera que se asume como "científica".

En 1882 Ignacio Manuel Altamirano escribió un prólogo al libro Viaje al Oriente de Luis Malanco que me parece interesante porque señala el momento de transición entre dos formas de escribir crónicas de viajes. En el prólogo de

${ }^{23}$ David Harvey, The Condition of Posmodernity: An Enquiry into the Origins of Cultural Change, Cambridge, Basil Blackwell, 1989, p. 254.

${ }^{24}$ Jens Andermann, Mapas de poder: una arqueología del espacio literario argentino, Rosario, Beatriz Viterbo, 2000, p. 38.

25 Véase Graciela Montaldo, Ficciones culturales y fábulas de identidad en América Latina, Rosario, Beatriz Viterbo, 1999. 
Altamirano, la introducción del ferrocarril es vista de manera favorable, dado que esa nueva movilidad que trae consigo se percibe como una oportunidad para refundar una tradición de escritura de viajes que en México ha sido poco productiva: "Los mexicanos viajan poco, y los que viajan, no escriben, ni publican sus impresiones o sus recuerdos." ${ }^{\text {26 }}$ Altamirano explica la razón de dicha renuencia a los viajes a partir de los tres siglos de historia colonial en la que la necesidad del desplazamiento dejó de existir. El prólogo de Altamirano es una exhortación implícita al viaje y, sobre todo, a la escritura de viajes; para ello considera necesario que se recuperen los momentos más itinerantes de la historia mexicana, en particular los desplazamientos de los dos "pueblos" que fundaron la nacionalidad mexicana, el español y el azteca: "dos razas esencialmente móviles y atrevidas."27 Por ello, dedica gran parte del prólogo a hacer un recuento de la historia de la movilidad mexicana y del desarrollo de los transportes en México; lo primero para demostrar que el viaje está en la raíz de la nación mexicana, y lo segundo, para mostrar que el desarrollo del transporte facilitará ahora los recorridos de los viajeros que quieran conocer el país, porque para Altamirano el territorio todavía es ignorado en su mayor parte, y necesita ser visitado, estudiado, "leído":

[...] lo que se llama, en fin hoy, el suelo mexicano, es un vasto libro en el que la vista vulgar no lee sino la página más reciente, pero en el que los ojos penetrantes del antropologista y del anticuario descubren páginas más antiguas y que se pueden estudiar todavía como los caracteres más borrados de un palimpsesto. ${ }^{28}$

A Altamirano le interesan los viajes masificados de los turistas, pero le interesan más los viajes letrados que "interpreten", que arrojen luz sobre el territorio y su historia. Aunque está consciente de que el desarrollo de la tecnología del transporte ha facilitado los viajes al extranjero, cree que es necesario que se

\footnotetext{
${ }^{26}$ Ignacio Manuel Altamirano, "Prólogo al Viaje a Oriente de Luis Malanco", en José Luis Martínez, La literatura nacional: revistas, ensayos, biografías y prólogos, México, Porrúa, 1949, vol. 3, p. 95.

27 Ibid., p. 96.

${ }^{28}$ Ibid., pp. 101 y 102.
} 
siga recorriendo el "territorio nacional" y se escriban relatos que enriquezcan la pobre tradición mexicana de literatura de viajes, de la cual hace también un recuento en el prólogo. Altamirano parece percibir una tendencia, hacia finales del siglo xIX, al menosprecio de lo nacional en un momento que se quiere vivir de manera cosmopolita:

Figúrasenos que hablar de nuestras poblaciones, de nuestras montañas, de nuestros ríos, de nuestros desiertos, de nuestros mares, de nuestras costumbres y de nuestro carácter, es asunto baladí, y que al ver escrito en una página de viaje un nombre indio, todo el mundo aquí ha de hacer un gesto de desdén [...]. Hay cierta repugnancia para conocer el país nativo, y ésta es la causa de que no puedan desarrollarse vigorosamente todas las ramas de nuestra literatura nacional. Sólo el tiempo y la civilización harán desaparecer éstos que son hábitos de la vida colonial. ${ }^{29}$

La visión telúrica que tiene Altamirano de la literatura nacional le hace concebir el relato de viajes como un género útil en la construcción de su programa literario. Sin embargo, me parece que en realidad dicho programa opera sólo de manera retrospectiva, es decir, que se refiere a una crónica de viaje practicada a la manera de Manuel Payno o Guillermo Prieto, pero que no parece que podría arraigarse en las décadas por venir. Ejemplos de ello son precisamente las crónicas de Nájera, las cuales van a contracorriente de esa poética del relato de viajes que a Altamirano le gustaría implantar.

Altamirano cree que la literatura puede enseñar mejor que los áridos libros de geografía: "En el interior, [la literatura de viajes] habría sido utilísima para hacernos conocer nuestra propia geografía. Sabido es que en esta materia enseñan más los libros de viajes que los libros metódicos en que se contienen datos, aunque precisos, áridos para la imaginación y difíciles para la memoria" 30 En 1882, sin embargo, Altamirano no podía vislumbrar el desarrollo de las instituciones geográficas que se desplegaría durante el porfiriato y cuyos programas estaban orientados, entre otros objetivos, a la difusión de la imagen geográfica

${ }^{29}$ Ibid., pp. 114 y 115.

${ }^{30}$ Ibid., p. 113. 
del país en el nivel masivo. Altamirano tampoco podría preveer que el poder visual de los mapas comenzaría a desplazar a las crónicas de viaje en su fijación discursiva del territorio. En última instancia, aquello que por razones temporales escapa a Altamirano, pero que los escritores de la nueva generación comenzarán unos años más tarde a practicar en su escritura, es que la geografía a finales del siglo xIx es ya un discurso que ha adquirido una centralidad que antes poseía la letra.

\section{VIAJE AL INTERIOR (MODERNISTA)}

El "periodo modernizador" (1870-1910), como lo definió Ángel Rama, se caracterizó por la instauración en las sociedades latinoamericanas de valores materialistas y mercantilistas que trastocaron el lugar de la literatura y de los escritores.$^{31}$ Las nuevas oligarquías capitalistas revocaron los tradicionales mecenazgos a los escritores aún antes de que pudiera desarrollarse un mercado editorial, ${ }^{32}$ lo que los obligó al trabajo periodístico como forma de subsistencia. La progresiva especialización del trabajo intelectual, modelada por "los planes de estudio de la universidad positivista", acentuó la marginación del grupo letrado que ya no podía abarcar todos los campos del conocimiento. ${ }^{33}$ Quizá es esta creciente marginación del trabajo literario la que está detrás del malestar de Gutiérrez Nájera en su diagnóstico de la literatura mexicana en 1881:

[...] no hay un solo periódico literario, si exceptuamos la edición semanaria de El Nacional, única que se atreve entre la tos asmática de las locomotoras, el agrio chirriar de los rieles y el silbato de las fábricas, a hablar de los jardines de Academus, de las fiestas de Aspasia, de los árboles del Pireo, en el habla sosegada y blanda de los poetas. ${ }^{34}$

31 Para un análisis amplio sobre el periodo y sobre el lugar del artista en la sociedad capitalista, véase Ángel Rama, Rubén Darío y el modernismo, especialmente los primeros dos capítulos.

32 Cfr. Perus, op. cit.

33 Ángel Rama, La ciudad letrada, Santiago, Tajamar, 2004, p. 132.

${ }^{34}$ Manuel Gutiérrez Nájera, "El movimiento literario en México" [1881], en Obras I, p. 372. 
En el ámbito estético, esta crisis de las letras a finales de siglo produjo un intento por preservar, ante el avasallante mercantilismo, el ideal de belleza en la literatura y en particular en la poesía. Surgió un nuevo culto a la belleza que enriqueció el "instrumento poético" a través de la incorporación de la tradición poética del Siglo de Oro y de los "elementos mitológicos de la tradición grecolatina". ${ }^{35} \mathrm{Al}$ mismo tiempo, la pérdida del carácter pedagógico de la literatura y una exigencia menor en cuanto a la representación nacional y regional, predispuso a los escritores a una actitud más individualista. Se desarrolló también una fuerte inclinación internacionalista que reclamaba el derecho a "cualquier escenario del universo" ${ }^{36}$ Gutiérrez Nájera expresó este reclamo de muchas formas; en un artículo de 1885, escribe: "Hoy no puede pedirse al literato que sólo describa los lugares de su patria y sólo cante las hazañas de su héroes nacionales. El literato viaja, el literato está en comunicación con las civilizaciones antiguas y con todo el mundo moderno." ${ }^{37}$

Para los escritores modernistas los viajes fueron importantes como práctica cultural y también como metáfora literaria. En Gutiérrez Nájera, muchas veces en tono humorístico, el viaje aparece más como metáfora del viaje de la imaginación que como experiencia vital. En su obra proliferan las referencias a las incomodidades de los desplazamientos y muestra una preferencia porque el exterior venga hacia él en forma de libro. Así lo expresa en el artículo que dedicó al libro Notas y episodios de viaje a los Estados Unidos (1884) de Alberto Lombardo y donde también exhibe su familiaridad con la tradición de la literatura de viajes romántica. Del mismo modo que Altamirano, Gutiérrez Nájera critica la ausencia de una literatura de viajes: "En México, este género literario está tan atrasado o más que los otros. Aquí ninguno viaja." ${ }^{38}$ La razón, en parte, para esta falta es, de nuevo, la marginación económica de los escritores: "iQué van a via-

35 Perus, op. cit., p. 80.

36 Ángel Rama, Transculturación narrativa de América Latina, México, Siglo XXI, 1982, p. 14.

${ }^{37}$ Citado en Belem Clark de Lara, Tradición y modernidad en Manuel Gutiérrez Nájera, México, UNAM, 1998, pp. 240 y 241.

${ }^{38}$ Manuel, Gutiérrez Nájera, "Notas y episodios de viaje a los Estados Unidos de Alberto Lombardo" [1884], en Obras I, p. 232. 
jar los literatos!, si llevan la vida más aporreada que puede darse, y solamente salen fuera de garitas cuando les dan un empleíllo diplomático, o les destierra el gobierno por haberse metido a politicastros revoltosos". ${ }^{39}$

En el caso de Gutiérrez Nájera, la ironía de esta fascinación modernista por los viajes es que él no tuvo que viajar a Europa o Estados Unidos para sentirse en sintonía con la "civilización moderna". Quizá la expansión de la red ferroviaria en México a finales de siglo influyó en la manera de percibir la cercanía con los centros hegemónicos:

No soy de aquellos pesimistas que ven en cada progreso material que nuestra patria realiza un peligro para su independencia, y la noticia de haber sido terminada la vía férrea que une a la capital de la República con Nueva York está muy lejos de haberme causado un mal rato. Veo en este hecho el término de nuestro aislamiento del resto del mundo, la participación que tomamos en el gran concierto de la civilización. ${ }^{40}$

El año de 1884, en el que Gutiérrez Nájera publica el artículo sobre el libro de viaje de Lombardo, es muy importante para el régimen porfirista, porque en ese entonces se completó la vía del ferrocarril que unía la ciudad de México con El Paso. ${ }^{41}$ La prensa siguió muy de cerca estos acontecimientos, y muchos de los periódicos donde Gutiérrez Nájera colaboraba participaron del entusiasmo, notablemente La Libertad, el periódico dirigido por Justo Sierra, y donde Nájera publicó varias de sus crónicas de viaje.

Gutiérrez Nájera no alcanzó a reunir sus crónicas de viaje dispersas en los numerosos periódicos para los que colaboró, aunque tenía proyectado un libro al que titularía "Viajes extraordinarios", del que por cierto escribió el prólogo. La ironía del título se hace explícita en el prólogo: el autor se niega a publicar su libro de viajes, y prohíbe tajantemente que otros lo publiquen por él porque tiene miedo a la fama que ello le pueda acarrear, debido a que lo pondrían al lado de los grandes exploradores de la historia. Y también solicita que no se le incluya

\footnotetext{
39 Loc. cit.

${ }^{40}$ Citado en Pérez Gay, op. cit., p. xxxi.

${ }^{41}$ Claude Dumas, Justo Sierra y el México de su tiempo, México, unam, 1992, t. II, p. 221.
} 
en los diccionarios de viajeros célebres. En un "gesto de cortesía" con sus lectores, el autor accede a publicar sólo parte de su libro de viajes extraordinarios. La ironía de Nájera es interesante porque formula de otra manera esa pérdida de legitimidad del relato de viajes de que hablamos antes. El prólogo de Nájera, me parece, anuncia de manera irónica el fin de la era de las grandes exploraciones y el comienzo de la era turística.

Rafael Pérez Gay ha reunido lo que pudo haber sido ese libro inédito. Consiste de cinco crónicas de viajes en tren a Puebla (1880), Guanajuato (1882), Toluca (1890) Cuernavaca (1891) y Jalapa (1892).${ }^{42}$ El periodismo de finales de siglo que posibilitó la profesionalización del escritor, en el caso de la crónica dictó en gran medida la forma que ésta adoptó. Las crónicas de viaje de Nájera reproducen los rasgos que exige la nueva cultura periodística: muestran un "aligeramiento" respecto a la crónica de mediados de siglo, se reduce considerable la extensión para ajustarse a los espacios del periódico, se abandonan las pretensiones de erudición y se descartan las aspiraciones transformadoras. Nada más alejado de ese programa que Altamirano le quería asignar al relato de viajes.

Las crónicas de Gutiérrez Nájera responden claramente al pragmatismo de la escritura periodística; las cinco incluidas en "Viajes extraordinarios" son productos de viajes que hizo para cubrir ceremonias cívicas, tomas de posesión de un gobernador o reuniones con gobernantes locales; tres de ellas (Cuernavaca, Toluca y Jalapa) y la última parte de la crónica sobre Puebla fueron publicadas en el periódico que fungiría en la práctica como el órgano de difusión del porfiriato, El Partido Liberal (1885-1896), ${ }^{43}$ de ahí que no extrañen los elogios que

${ }^{42}$ José Luis Martínez incluye, en la sección "Notas de viaje" de su antología de la obra de Nájera, otras crónicas de viajes por el interior del país no consideradas por Pérez Gay: "Guadalajara", "Lago de Pátzcuaro", "Viaje alrededor de las veracruzanas" y "Morelia".

43 Adela Pineda describe de la siguiente manera las filiaciones ideológicas de El Partido liberal: "[...] periódico subvencionado por el porfiriato, fue uno de los principales vehículos para consolidar el liberalismo institucionalizado de este periodo a través de la construcción de mitos y emblemas, como los que encarnaron las personas de Benito Juárez y del mismo Díaz", "Positivismo y decadentismo: el doble discurso en Manuel Gutiérrez Nájera y su Revista Azul, 18941896.", en Claudia Agostoni y Elisa Speckman [eds.], Modernidad, tradición y alteridad: la ciudad de México en el cambio de siglo (XIX-XX), México, IIH-unam, 2001, p. 195. 
Nájera dedica a los gobernantes porfiristas locales. En la última frase de la crónica de Puebla escribe, después de relatar la ceremonia pomposa de la toma de posesión del gobernador: "En Puebla dejo un bien querido gobernante". ${ }^{44}$ En la crónica de Toluca hace un relato más o menos detallado de los "avances" culturales promovidos por el gobernador José Vicente Villada: "El gobernador del estado de México es coronel, pero merece que lo asciendan a general. Ha dirigido y ganado una batalla, la de la instrucción en pugna con la ignorancia". ${ }^{45}$ En la crónica de Guanajuato hace una lista de las "personalidades" a las que acompaña en el viaje: "[...] el señor Díez Gutiérrez, que ya desde el estado que con tan grande tino gobernaba o desde el ministerio que dignamente desempeña, ha servido a la causa de la paz y del progreso; el señor Baranda, que depurando la administración de justicia y difundiendo la instrucción hace duraderas y sólidas las conquistas materiales". 46

Si se fijaran en un mapa los viajes de Gutiérrez Nájera, como propone Franco Moretti en su análisis de la novela europea, descubriríamos que su escritura ocurre precisamente en la geografía integrada a la red ferroviaria: Guanajuato, Toluca, Jalapa, Cuernavaca. ${ }^{47} \mathrm{El}$ cronista no elige para sus viajes ningún otro lugar adonde no se llegue en ferrocarril, de manera que "el espacio semiótico" en torno al cual se organizan sus crónicas es precisamente el espacio modernizado promovido por el porfirismo, y cuya expresión cartográfica más elocuente es el mapa de Calderón (fig. 1). Y en este sentido el mapa de Calderón y las crónicas de Gutiérrez Nájera establecen una relación, que Angenot llamaría interdiscursiva, en que el espacio nacional aparece como una red. ${ }^{48}$

${ }^{44}$ Manuel Gutiérrez Nájera, "Viajes extraordinarios", en Rafael Pérez Gay [ed.], Manuel Gutiérrez Nájera, México, Cal y Arena, 1996, p. 505.

45 Ibid., p. 509.

46 Ibid., p. 483.

47 Franco Moretti propone la elaboración de mapas, no como ilustraciones a los textos, sino como herramientas de análisis literario, dado que "los mapas ponen de manifiesto la lógica interna de la narración: el espacio semiótico de la trama, en torno al cual la narración se auto-organiza", p. 7.

48 Craib analiza la proliferación de "mapas de redes" (networkmaps) que proliferaron durante la última década del siglo xIx en México, cuyo objetivo principal era mostrar a un país conectado por múltiples caminos, líneas ferroviarias, telegráficas y portuarias, y así mostrar a los inver- 
Por esa razón en las cinco crónicas, las referencias al viaje en tren ocupan un lugar central. En la crónica del viaje a Guanajuato, por ejemplo, gran parte del texto está dedicado a él. Dividida en tres partes, sólo la última, y la más breve, está dedicada a la descripción de la ciudad, mientras que la primera relata los preparativos para llegar a la estación del tren, y la segunda, el viaje en el tren mismo, con una larga referencia a la construcción de las vías del ferrocarril del Pacífico en Estados Unidos. Para el cronista, la "empresa colosal" de unir el centro con la costa pacífica, dada su dificultad, es una tarea sólo comparable a los trabajos de los héroes clásicos. Esta larga digresión, antes de comenzar la narración de su primer viaje en tren, dota a su experiencia de viaje de una genealogía euronorteamericana e integra su desplazamiento a la red ferroviaria occidental. Al igual que el mapa de Calderón, que enfatiza las rutas ferroviarias y marítimas, y señala la conexión de México con Estados Unidos, las crónicas de Gutiérrez Nájera relatan, al nivel de la experiencia personal, ese vínculo con los centros hegemónicos celebrado por la élite porfirista.

En la misma crónica del viaje a Guanajuato, la descripción que hace Gutiérrez Nájera del tren que está a punto de abordar se instala nuevamente en los tópicos mitológicos. El cronista-poeta está convencido de que el tren está llamado no sólo a revolucionar el mundo material sino que, en un gesto que ya anuncia el futurismo, cree que su imagen se puede unir al repertorio cultural y poético de Occidente:

La poesía puede volar con alas mecánicas, que no se derriten como las de Ícaro. Ya el Pegaso - ese pobre Maretzeck de la mitología - está flaco y enfermo: un vicario le monta para ir a decir misa en las aldeas circunvecinas del curato; pero en cambio ahora tenemos un hipogrifo de hierro para el que no hay obstáculos ni abismos, que no tiene alas, porque las alas son inútiles, y en cuyo vientre de Titán chispea y crepita el fuego que Prometeo robó a los dioses. ${ }^{49}$

sionistas que el país poseía, en términos de Engels, "los medios de comunicación adecuados a los modernos medios de producción", Craib, Cartographic..., p. 183.

${ }^{49}$ Ibid., p. 478. 
La elaboración de la metáfora del hipogrifo y el humor que permean toda la crónica la distinguen de la escritura periodística común, y la instalan en esa zona literaria buscada por los escritores modernistas en su trabajo en la prensa. A través de la exhibición culterana - el "enriquecimiento poético" lo llama Perus - y la búsqueda de la belleza en el mundo tecnológico se trataba de reinsertar la literatura, y más concretamente la poesía, dentro del espacio público, al mismo tiempo que se intentaba, si no ya restaurar el lugar central del escritor, al menos mantener su vigencia como voz autorizada dentro de un medio cada vez más desinteresado por la palabra literaria. ${ }^{50} \mathrm{Y}$ es quizá en este interés en el mundo moderno en que la crónica de viaje recupera su vigencia frente a la emergencia de los discursos especializados sobre el espacio. La crónica de viaje se convierte en el instrumento que permite atestiguar ese "progreso" traído por la modernización.

Gutiérrez Nájera no se resigna a la intemperie a que promete conducir la nueva hegemonía de los valores mercantilistas a la poesía y a los escritores y encuentra en el tren mismo un sucedáneo del interior modernista: ${ }^{51}$

Íbamos en un wagon especial, cómodos, perfectamente cómodos. Yo, arrellanado como un sátrapa en los acolchonados almohadones, calada montera de viaje, subido el cuello del paletot, las manos semihundidas en unos guantes afelpados y cubierto, como los héroes de Virgilio, por una espesa nube de humo $[\ldots]$, el humo que me rodeaba procedía de un puro enorme detrás del cual se hallaba este humilde y sincero servidor de ustedes. ${ }^{52}$

${ }^{50}$ Susana Rotker explora ampliamente la condición literaria de la crónica modernista y señala el alto sentido poético que tenían muchas de ellas, Susana Rotker, Fundación de una escritura: las crónicas de José Martí, La Habana, Casa de las Américas, 1992, véanse especialmente las pp. 134-140.

${ }^{51}$ Aquí hago referencia a la discusión sobre el concepto de autonomía literaria que plantea Julio Ramos. El interior modernista, simbolizado por el soneto "De Invierno" de Rubén Darío, en el que la habitación a la que ingresa el sujeto representa el lugar propio de la literatura, "el interior estético", frente al afuera, que es el terreno de la vida urbana, la política, la economía, la modernidad. Ramos, op. cit., p. 91.

${ }^{52}$ Ibid., p. 492. 
Si el tren anula las distancias entre una ciudad y otra, también establece una continuidad entre el interior burgués y el vagón de pasajeros: "Hoy no se viaja, la locomotora nos arrastra con casa y todo. El viajero puede llevar sus libros, sus pantuflas, su mujer y su gato. Parece que no vamos camino de Guanajuato, sino que Guanajuato viene hacia nosotros". ${ }^{53}$ En la crónica de Gutiérrez Nájera, el tren no aparece pues como un afuera amenazante del orden estético, sino como un sucedáneo del recinto interior de la poesía. ${ }^{54}$

La única amenaza a este interior es lo que está afuera del tren y de las vías férreas, es decir, aquello que atenta contra la modernidad: "Los indios estorban, en cuanto pueden, el tránsito de los trenes por la vía." "55 El tren entonces refunda la noción de frontera: la separación no se establece entre, por ejemplo, la parte norteamericana de las vías del tren y la parte mexicana; sino entre aquello que está dentro del tren y lo que está afuera, es decir, entre aquello sancionado por la civilización y aquello contra lo que se avanza. Las crónicas de Gutiérrez Nájera, de la misma manera que el mapa de Calderón, donde no está tan claramente marcada la frontera con Estados Unidos, cumplen el propósito de señalar la fluidez y conexión del espacio nacional.

\section{INVENTAR(IAR) CIUDADES}

La descripción literaria de una ciudad comienza, como ha señalado Luz Aurora Pimentel, con el nombre que la designa; en él están contenidos la referencia al lugar geográfico que nombra, los códigos culturales que le han sido asignados históricamente y los saberes provenientes de discursos oficiales y populares. ${ }^{56}$ En sus crónicas, Gutiérrez Nájera da cuenta de los tópicos que se han fijado en

53 Ibid., p. 485.

${ }^{54}$ Para una exploración más amplia de la fascinación modernista por el interior burgués y sus contradicciones, véase Rotker, op. cit., p. 76.

55 Ibid., p. 480.

${ }^{56}$ Luz Aurora Pimentel, El espacio en la ficción. Ficciones espaciales: la representación del espacio en los textos narrativos, México, unam/Siglo XXI, 2010, p. 33. 
torno a las ciudades que describe; por ejemplo, de Guanajuato refiere la historia minera y la opulenta arquitectura; de Puebla, la semejanza con la ciudad de México, el dinamismo del comercio y la presencia notable de las iglesias; de Jalapa, la larga tradición literaria sobre la ciudad (Altamirano, Juan de Dios Peza, Guillermo Prieto, José María Roa Bárcena, José María Esteva), y de Cuernavaca, el calor y la huella cortesiana. Sin embargo, Nájera renuncia a toda forma de generar un saber; en sus crónicas ha desaparecido el vínculo que las crónicas de mediados de siglo mantenían con el discurso geográfico. No hay datos, información, estadísticas, erudición. No se siente obligado a informar a su lector porque sabe que en los libros de viaje "aparecen el lugar, el campo, el paisaje, la marina, la ciudad, el pueblo, el villorrio, el monumento artístico, no tal como son, sino tal como los sintió el temperamento del viajero." ${ }^{57}$

Con esta premisa y con la conciencia de que "la belleza que percibimos es un triángulo cuyas tres líneas componentes son: el objeto mismo, el que lo mira y el instante en que lo mira", ${ }^{58}$ Gutiérrez Nájera elabora una descripción metafórica de las ciudades que visita. ${ }^{59}$ De Guanajuato, por ejemplo, dice que es "una ciudad dislocada", en la que "los duendes, en una noche de borrachera, jugaron a la pelota con las casas", y más adelante: "... es una gran colmena escalonada en la montaña" y "una mina al aire libre"; ${ }^{60}$ Puebla es una ciudad "netamente levítica" y Cuernavaca es un "infierno", un "Sudatorium", y es Proserpina, "la reina de este infierno que se llama la tierra caliente." ${ }^{\text {61 }}$ La descripción de Jalapa, acaso por la tradición literaria que la precede, es la más poética de todas; se trata de una suerte de "composición en blanco" en la que se reiteran los motivos de la niebla, la humedad y la luz que envuelven a la ciudad. Es claro que la elaboración metafórica de Gutiérrez Nájera transforma la "realidad" de las ciudades que describe donde "la imagen del espacio proyectado ya no embona en una reali-

\footnotetext{
${ }^{57}$ Gutiérrez Nájera, "Viajes Extraordinarios...", p. 514. Cursivas en el original.

58 Ibid., p. 515.

59 Para un análisis detallado sobre las modalidades de la descripción de los espacios, y en particular la modalidad metafórica, véase Pimentel, op. cit., pp. 89-100.

${ }^{60}$ Gutiérrez Nájera, "Viajes Extraordinarios...", p. 487.

${ }^{61}$ Ibid., p. 531.
} 
dad propuesta como idéntica, sino que se proyecta sobre la tela de fondo de otra realidad posible, dando a luz a una criatura híbrida y plenamente textual" ${ }^{62}$ La precisión de las metáforas (la topografía, la arquitectura, el clima) retrata la "realidad" de las ciudades, pero al mismo tiempo agregan una riqueza de sentido que los otros discursos sobre el espacio, el cartográfico más particularmente, no poseen.

Estas "criaturas híbridas" que son las crónicas de Gutiérrez Nájera me parece que funcionan en dos niveles: por un lado son "plenamente textuales", material literario y poético que se suma a la tradición de la literatura de viajes, y por otro, cumplen la misión de ser también un discurso sobre el espacio dentro del contexto porfirista. Es cierto que estamos frente a una crónica de viaje diferente a las crónicas de mediados de siglo que operaban, a decir de Graciela Montaldo, como "verdaderas máquinas territorializadoras", en cuyos relatos de relevamientos se integraban nuevos espacios a la nación, sin embargo, integradas al discurso social porfirista, las crónicas de Nájera contribuyen a la creación no sólo de la idea de un espacio nacional sino a la proyección de un espacio que se percibe como moderno. El ejemplo más notable es la crónica de su viaje a Toluca. El motivo del viaje responde a la coyuntura de las ceremonias políticas de la élite porfirista; el cronista viaja con una comitiva de periodistas para atestiguar los logros del gobernador del Estado de México, José Vicente Villada. La crónica comienza con un inventario de las numerosas carencias de Toluca: "no es precisamente hermosa", "no la abraza el mar", "ninguna gran sombra histórica la habita", "ninguna catedral yergue sus torres macizas", ${ }^{63}$ carencias que se acrecientan frente a un escenario nacional pleno de ciudades admirables:

Tampico parece la amada de los peces, la del hermoso río, la de las náyades desnudas. Guadalajara es andaluza, tiene ojos negros y mantilla blanca y navaja en la liga para herir a los amigos de la libertad. Mérida, la opulenta señora del henequén, la ricahembra, tiene su estruendoso, alegre carnaval, como Venecia, y sus

${ }^{62}$ Pimentel, op. cit., p. 90.

${ }^{63}$ Gutiérrez Nájera, "Viajes Extraordinarios...," p. 505. 
grandes poetas como la antigua Florencia. Tlaxcala es una tumba. Guanajuato, una mina, la caverna deslumbrante de Aladino. San Luis trabaja con buen humor y primorosamente viste los domingos. Chilpancingo es montaña, la cúspide inaccesible de Guerrero. Monterrey y San Cristóbal son vigías, centinelas avanzados. ${ }^{64}$

La enumeración es larga e incluye referencias a Cuautla, Cuernavaca, Querétaro, Mazatlán, Morelia, Veracruz, Jalapa y Oaxaca; su propósito es incorporar la ciudad de Toluca a esa mapa nacional que el cronista ha elaborado a partir de la descripción paratáctica del territorio. La manera en que Toluca se integra al espacio nacional es a partir de su modernidad: "No es monumental, no es arcaica: es joven. Tiene la frescura, la sonriente mocedad de una muchacha que sabe ataviarse y vestirse con muselina, con percal, con listones vistosos [...]. Ningún convento la ensombrece; ninguna iglesia pesada la magulla. ${ }^{65}$ Toda está flamante y nuevecita", ${ }^{66}$ y más adelante: "Gusto europeo y moderno revelan sus construcciones, todas limpias todas elegantes" ${ }^{67}$ Esta imagen de una ciudad percibida como moderna es reforzada por las observaciones del cronista sobre la labor educativa del gobernador del Estado de México, quien, según Nájera, ha modernizado el estado gracias a la instrucción: "Así como el aspecto de Toluca es netamente moderno, así también netamente moderno es el carácter moral de sus escuelas". ${ }^{8}$ Toluca es pues en la crónica de Gutiérrez Nájera la ciudad porfirista por excelencia: moderna y positivista.

\footnotetext{
${ }^{64}$ Ibid., p. 506.

${ }^{65}$ Hay en las crónicas de viaje de Gutiérrez Nájera un desdén por los monumentos religiosos que puede deberse a que "recuerdan la dominación española", ibid., p. 507, pero también responden, me parece, a un discurso social que ha instaurado como hegemónica la visión positivista de la sociedad.

${ }^{66}$ Loc. cit.

${ }^{67}$ Loc. cit.

${ }^{68}$ Ibid., p. 510.
} 


\section{CONCLUSIÓN}

Manuel Gutiérrez Nájera incumple la tarea que Altamirano le exigía a los viajeros por venir: la de ser "intérpretes" de ese palimpsesto que era el espacio nacional. En primer lugar porque su escritura se despliega en la época de las especializaciones y los especialistas, y esa tarea acaso esté ahora asignada a geógrafos y antropólogos; en segundo, porque su generación ha reclamado para ellos la libertad a una práctica literaria cosmopolita. La generación de Gutiérrez Nájera está lejos de repetir los gestos reformadores de los liberales pre-porfiristas a la que perteneció su maestro Altamirano.

Una escena que se repite en al menos tres de sus crónicas explica, en parte, el lugar de Gutiérrez Nájera y de su literatura frente al régimen porfirista. Al describir el transcurso del viaje en ferrocarril a Guanajuato, Puebla y a Toluca, el cronista enlista los nombres de sus compañeros de viaje, como ya hemos mencionado antes, varios de ellos intelectuales como él, pero que mantienen un vínculo más cercano con el régimen porfirista (los más notables, Vicente Riva Palacio y Alfredo Chavero), pero también funcionarios públicos y políticos porfiristas (Carlos Pacheco, Carlos Díez Gutiérrez, Joaquín Baranda, gobernadores los dos primeros y ministro de instrucción pública el último). Esta cercanía con el poder político produjo, como explica Ángel Rama, un cierto tipo de literatura: "[...] los escritores [modernistas] que se incorporaron, ya fuera como directos funcionarios, ya como laxos sostenedores, ya como discretos compañeros de viaje, a la ciudad letrada de la modernización, y fue la gran mayoría, se aplicaron a dos géneros literario-políticos principales[...]"; esos dos géneros fueron el "propagandístico en cualquiera de sus ramas" y la filosofía política. ${ }^{69}$

Como "compañero de viaje" de la ciudad letrada modernizada, Gutiérrez Nájera hizo de sus crónicas vehículos de exhibición y difusión de los "logros" del régimen porfirista, sobre todo en términos de la reorganización del espacio nacional, a partir de la introducción y expansión de los ferrocarriles (Guanajuato), pero también en relación con los avances educativos (Toluca) y el desarrollo co-

${ }^{69}$ Ángel Rama, La ciudad letrada..., pp. 143 y 144. 
mercial (Puebla). El discurso territorial que emana de ellas coincide con el del régimen porfirista en el sentido en que ambos imaginan un espacio nacional más cercano a los centros hegemónicos del norte. A diferencia de los discursos territoriales del pasado que imaginaban el espacio de la nación como contenido, cerrado y soberano, este nuevo discurso imagina la nación con unas fronteras borrosas, pero no por falta de límites, sino por su conexión con la modernidad occidental.

Recibido: 24 de noviembre, 2011. Aceptado: 16 de julio, 2012.

BibliografíA

Alonso, Carlos J., The Burden of Modernity: The Rethoric of Cultural Discourse in Spanish America, Nueva York, New York up, 1998. , The Spanish American Regional Novel: Modernity and Autochthony, Cambridge, Cambridge UP, 1990.

ANDERMANn, Jens, Mapas de poder: una arqueología del espacio literario argentino, Rosario, Beatriz Viterbo, 2000.

Angenot, Marc, "Social Discourse Analysis: Outlines of a Research Project", en The Yale Journal of Criticism, 17.2, 2004, pp. 199-215.

Altamirano, Ignacio Manuel, "Prólogo al Viaje a Oriente de Luis Malanco", en José Luis Martínez [ed.], La literatura nacional: revistas, ensayos, biografías y prólogos, México, Porrúa, 1949, vol. 3, pp. 93-122.

ClaRK DE LARA, BelEM, Tradición y modernidad en Manuel Gutiérrez Nájera, México, unam, 1998.

Craib, Raymond B., Cartographic Mexico: A History of State Fixations and Fugitive Landscapes, Durham, Duke UP, 2004. 
, "El discurso cartográfico en el México del porfiriato", en Héctor Mendoza Vargas y Michel Antochiw [eds.], México a través de los mapas, México, Instituto de Geografía-unam, 2000, pp.131-150.

Dumas, Claude, Justo Sierra y el México de su tiempo, t. II, México, unam, 1992. García Martínez, Bernardo, "La Comisión Geográfico-Exploradora", en Historia mexicana, núm. 96, abril-junio 1975, pp. 485-555.

González, Lus, "El liberalismo triunfante", en Historia General de México, México, Centro de Estudios Históricos-El Colegio de México, 1998, vol. 2, pp. 897-1016.

GuTIÉRREZ NÁjERA, Manuel, "El movimiento literario en México" [1881]. En Obras I. , "Notas y episodios de viaje a los Estados Unidos de Alberto Lombardo" [1884], en Obras I.

, Ernesto Mejía Sánchez [ed.], Obras I. Crítica Literaria, México, unAM, 1995.

, "Viajes extraordinarios", en Rafael Pérez Gay [ed.], $M a-$ nuel Gutiérrez Nájera, México, Cal y Arena, 1996, pp. 469-536.

Harvey, David, The Condition of Posmodernity: An Enquiry into the Origins of Cultural Change, Cambridge, Basil Blackwell, 1989.

HolDEn, R. H., Mexico and the Survey of Public Lands: The Management of Modernization, 1876-1911, Dekalb, Northern Illinois UP, 1994.

Ighina, Domingo et al., Espacios geoculturales. Diseños de nación en los discursos literarios del Cono Sur. 1880-1930, Córdoba, Alción, 2000.

MarTínez, José Luis, "Estudios y antología general”, en Manuel Gutiérrez Nájera, Obras, México, FCE, 2003.

Montaldo, Graciela, Ficciones culturales y fábulas de identidad en América Latina, Rosario, Beatriz Viterbo, 1999.

Pérez Gay, Rafael, "Prólogo" a Manuel Gutiérrez Nájera, México, Cal y Arena, 1996 (Col. Los imprescindibles), pp. vii-xii.

Perus, FrançoIse, Literatura y sociedad en América Latina: el modernismo, México, Siglo xxI, 1976.

Pierssens, Michael, "A State of Social Discourse", en The Yale Journal of Criticism 17.2, trad. de Robert Barsky, 2004, pp. 255-261. 
Pimentel, Luz Aurora, El espacio en la ficción. Ficciones espaciales: la representación del espacio en los textos narrativos, México, unAm/Siglo XXI, 2010. PinedA, Adela, "Positivismo y decadentismo: el doble discurso en Manuel Gutiérrez Nájera y su Revista Azul, 1894-1896.", en Claudia Agostoni y Elisa Speckman [eds.], Modernidad, tradición y alteridad: la ciudad de México en el cambio de siglo (XIX-XX) México, Instituto de Investigaciones Históricas-unam, 2001, pp. 195-219.

RAMA, ÁNGEL, La ciudad letrada, Santiago, Tajamar, 2004. , Rubén Darío y el modernismo (circunstancia socioeconómica de un arte americano), Caracas, Universidad Central de Venezuela, 1970.

XXI, 1982.

,Transculturación narrativa de América Latina, México, Siglo

Ramos, Julio, Desencuentros de la modernidad en América Latina. Literatura y política en el siglo XX, México, FCE, 1989.

RoTKER, SuSANA, Fundación de una escritura: las crónicas de José Martí, La Habana, Casa de las Américas, 1992.

Tenorio-Trillo, Miguel, Artilugio de la nación moderna. México en las exposiciones universales, 1880-1930, México, FCE, 1998.

WALLERSTEIn, IMMANUEL, El moderno sistema mundial. La segunda era de gran expansión de la economía-mundo capitalista, 1730-1850, trad. de Jesús Albores, vol. 3., México, Siglo xxI, 1998. 